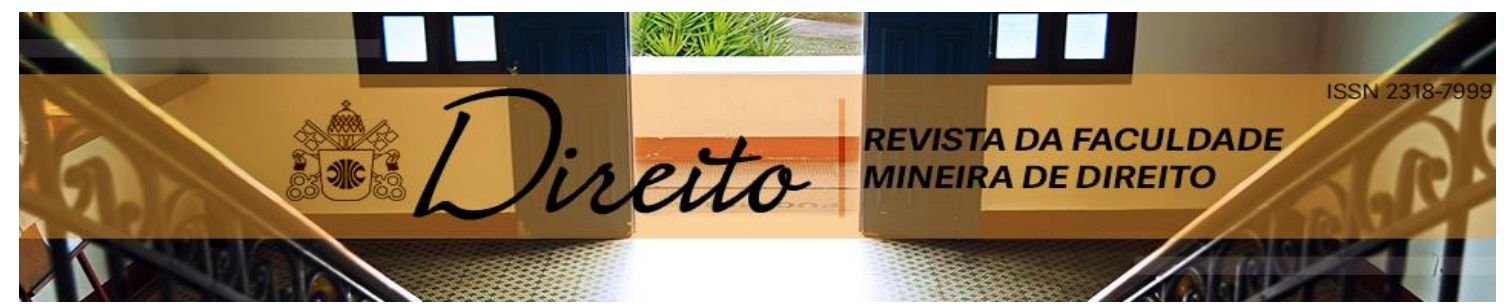

\title{
O CONFLITO ENTRE REDUÇÃO VERSUS PRORROGAÇÃO DA JORNADA DE TRABALHO: AS PROPOSIÇÕES DA TEORIA JURÍDICO-TRABALHISTA CLÁSSICA E DA TEORIA JURÍDICO-TRABALHISTA CRÍTICA, NO CONTEXTO DA REFORMA TRABALHISTA BRASILEIRA.
}

\author{
THE CONFLICT BETWEEN REDUCTION VERSUS EXTENSION OF WORKING HOURS: \\ THE PROPOSITIONS OF THE TRADITIONAL AND CRITICAL LEGAL-LABOUR \\ THEORIES IN THE CONTEXT OF BRAZILIAN LABOUR REFORM PLAN.
}

Everaldo Gaspar Lopes de Andrade ${ }^{1}$

Larissa Ximenes de Castilho²

\begin{abstract}
Resumo
O artigo objetiva desenvolver uma narrativa diferente sobre o tema prorrogação da jornada de trabalho. Por meio de uma versão analítica estruturante, parte da história da formação operária, para identificar a nova divisão social do trabalho e a aceleração da exploração da força de trabalho, no contexto do Modo de Produção Capitalista. Em seguida, analisa o embate entre prorrogação da jornada de trabalho, na experiência brasileira, a partir de uma análise entre a teoria tradicional e a teoria jurídico-trabalhista crítica. Por fim deixa transparecer a concepção desastrosa inserida da reforma trabalhista, que ampliará ainda mais a prorrogação da jornada de trabalho, o adoecimento e a morte lenta no trabalho, por meio da flexibilização.
\end{abstract}

Palavras-chave: Jornada de trabalho, hora suplementar, hora extra, flexibilização, teoria jurídicotrabalhista crítica.

\begin{abstract}
The article aims to develop a different narrative about the subject extension of the workday. Through a structural analytical version, starting from the history of the formation of the working class to identify the new social division of labour and the intensification of the exploitation of the labour force, in the context of the Capitalist method of production. Then parses the clashes about the extension of working hours in the Brazilian experience, between the traditional and the critical labor law theories. Finally lets on the disastrous labor reform entered design, which will broaden further the extension of working hours, the illness and slow death at work, by means of the flexibility and the prevalence of negotiated over the legislated.
\end{abstract}

Keywords: workday, extra time, overtime, flexibility, legal-labour critical theory.

Artigo recebido em 06 de fevereiro de 2017 e aprovado em 10 de abril de 2017.

1 Doutor em Direito e professor da Universidade Federal de Pernambuco, Recife, Pernambuco, Brasil.

${ }^{2}$ Mestranda em Direito pela Universidade Federal de Pernambuco, Recife, Pernambuco, Brasil.

RFMD, Belo Horizonte, v. 91, n. 39, p. 91-110, out./abr. 2017 - INSS 2318-7999 


\section{INTRODUÇÃO}

Este artigo objetiva demonstrar o conflito entre redução versus prorrogação da jornada de trabalho. Parte, inicialmente, para esclarecer como se deu a universalização/legitimação da jornada de trabalho. Para seus autores, surgiu inserida no cenário do Direito Dogmaticamente Organizado, típico da Sociedade Moderna. Tem como objetivo atender às exigências lançadas pela teoria macroeconômica liberal que começara a surgir, desde Adam Smith, que introduziu, pela primeira vez na história, uma concepção cientificamente organizada de Divisão Social de Trabalho.

O Modo de Produção Capitalista se legitima e se universaliza para subordinar a força do trabalho ao capital, na medida em que a burguesia não veio para ser hegemônica num determinado país ou região, veio para ser hegemônica em todo planeta, conforme denunciara, em 1848, o Manifesto do Partido Comunista que, por seu turno conclamava os operários de todos os países a se unirem.

A experiência legislativa brasileira não poderia ser diferente, na medida em que sofre os influxos, mesmo que tardiamente, da Revolução Industrial, e recepciona as diretrizes traçadas pela Organização Internacional do Trabalho.

Ao prosseguir sua narrativa, por meio de uma visão dedutiva, o texto chega à prorrogação da jornada de trabalho, para colocar frente à frente as versões da teoria jurídico-trabalhista tradicional e da teoria jurídico-trabalhista crítica.

Por fim, demonstrará as armadilhas e o retrocesso que estão inseridos na reforma trabalhista em curso no Congresso Nacional e a maneira como ela vai aprofundar ainda mais as possibilidades de adoecimento e as mortes lentas no trabalho, frutos de uma exploração ainda maior da força de trabalho, agora desarticulada e afetada pela desproletarização, clandestinização e, sobretudo, pelo desemprego estrutural. 


\section{A UNIVERSALIZAÇÃO/LEGITIMAÇÃO DO TRABALHO LIVRE/SUBORDINADO, DA SUBORDINAÇÃO DA FORÇA DO TRABALHO AO CAPITAL COMO LÓCUS PRIVILEGIADO DA SOCIABILIDADE.}

Ao consultar os manuais de Direito do Trabalho, nas seções que tratam da duração do trabalho, os leitores são apresentados aos conceitos de jornada, horário e tempo efetivo de trabalho que, em linhas gerais, são muito semelhantes. Nesse sentido, explica Maurício Godinho Delgado (2016) que,

Jornada de trabalho é expressão com sentido mais restrito [...] compreendendo o tempo diário em que o empregado tem de se colocar em disponibilidade perante seu empregador, em decorrência do contrato. O tempo, em suma, em que o empregador pode dispor da força de trabalho de seu empregado em um dia delimitado. [...]

Já a expressão horário de trabalho traduz, rigorosamente, o lapso temporal entre o início e o fim de certa jornada laborativa.

A Consolidação das Leis Trabalhistas, em seu Artigo 4ํㅜㄹ cuida da definição de tempo efetivo de trabalho, afirmando que se considera "como de serviço efetivo o período em que o empregado esteja à disposição do empregador, aguardando ou executando ordens, salvo disposição especial expressamente consignada. "Deixa-se aqui transparecer, de início, que a ideia de legitimação/universalização da compra e venda da força de trabalho ou da subordinação da força do trabalho ao capital surge na modernidade, com o advento da Revolução Industrial.

A partir daí, as relações de trabalho tomaram a forma que se conhece hoje, com o trabalhador vendendo sua energia de trabalho ao proprietário dos meios de produção, durante um tempo determinado e controlado, em troca de um salário. Surgiram nesse momento histórico o trabalho subordinado (emprego) e a jornada de trabalho como expressão da relação de subordinação entre empregador e empregado. Sobre o tema, escreveu um dos autores deste artigo:

A glorificação ou evangelização do trabalho assalariado fez surgir um modelo de sociedade marcadamente bipolar - capital versus trabalho -, e esta centralidade passou a ser não somente o ethos fundamental da convivência das pessoas em sociedade como também a priori da teorização no campo da sociologia clássica e do Direito do Trabalho. (ANDRADE, 2008. p.265.) 
Nesse sentido, o historiador E.P. Thompson (1998) explica que, nas civilizações pré-industriais a concepção de tempo era orientada por processos familiares no ciclo de trabalho ou nas atividades domésticas, como o tempo necessário para rezar um credo ou uma ave-maria em voz alta no Chile, por exemplo. $O$ trabalho era realizado em períodos alternados de atividade intensa e de ociosidade, característica que demonstrava o controle dos meios e processos do trabalho pelo trabalhador.

Aqui se está tratando do tempo de trabalho heterônomo, subordinado, prestado pelo empregado em favor de seu empregador. Importa também saber que tanto a definição de tempo de trabalho quanto de não-trabalho devem ser encaradas como construções sociais e que há uma multiplicidade de tempos sociais, como os tempos de lazer, de dedicação à família, de descanso, de estudo, etc. ${ }^{1}$

Somente no modo de produção capitalista o tempo de trabalho tornou-se o tempo dominante na sociedade, marcado pela rigidez, pela pontualidade, e pela coerção inerente às relações de subordinação entre empregados e empregadores. Essa visão do tempo de trabalho como único tempo socialmente valorizado, pautada na invisibilidade dos demais tempos sociais, ou ainda na sua condenação, tinha como objetivo eliminar as pausas e garantir ao capital o domínio dos outros tempos de vida do trabalhador, para obtenção do máximo de lucro. Considerando que o atual patamar de desenvolvimento tecnológico diminuiu o tempo necessário para finalizar os processos de trabalho deveria, logicamente, ter mais tempo livre disponível, desacelerando o ritmo de vida e permitindo que os trabalhadores se dedicassem a atividades diversas das laborativas, mas isto não aconteceu.

Mas, contrariando as expectativas, o que se pode perceber é que a jornada de trabalho não sofreu reduções significativas, após o incremento de produtividade decorrente da introdução das novas tecnologias da informação no mundo do trabalho. Este processo de aceleração tecnológica foi acompanhado, ao contrário do que se poderia imaginar, por uma intensificação do trabalho sem precedentes, que permite ao capital extrair uma quantidade cada vez maior de mais-valor. Além disso, foram introduzidas, no ordenamento jurídico-trabalhista brasileiro, ferramentas de

\footnotetext{
${ }^{1}$ Nesse sentido, ver: CARDOSO, Ana Claudia Moreira. Tempos de trabalho, tempos de não trabalho: vivências cotidianas de trabalhadores. 2007. Tese (Doutorado em Sociologia) - Faculdade de Filosofia, Letras e Ciências Humanas, Universidade de São Paulo, São Paulo, 2007. doi:10.11606/T.8.2007.tde-20032008101721. Acesso em: 2017-01-16.
} 
flexibilização, no campo da limitação legal de jornada - como o banco de horas e o Plano de Proteção ao Emprego.

Neste trabalho, os seus autores procurarão problematizar e desconstruir a versão da doutrina tradicional e da Organização Internacional do Trabalho acerca da redução da jornada de trabalho, predominantemente levada a efeito com redução de salários, e como estratégia para assegurar menores custos com mão-de-obra ao capital em momentos de crise econômica. Procuração também demonstrar a necessidade de retomar a luta pela redução de tempo de trabalho sem redução de salários, como ferramenta de enfrentamento do desemprego estrutural e como caminho para garantir aos trabalhadores e trabalhadoras a possibilidade de empregar o seu tempo livre na realização de atividades diversas do labor, como o lazer, a arte, o convívio familiar, etc.

\section{BREVE HISTÓRICO DA REGULAMENTAÇÃO DA JORNADA DE TRABALHO NO BRASIL.}

No Brasil, o processo de evangelização para o trabalho subordinado teve início com a Primeira República, expresso por meio da inserção, no Código Penal de 1890, do delito de vadiagem. De acordo com o Artigo 399 do referido diploma legal, considerava-se vadio aquele que:

Deixar de exercitar profissão, oficio, ou qualquer mister em que ganhe a vida, não possuindo meios de subsistência e domicilio certo em que habite; prover a subsistência por meio de ocupação proibida por lei, ou manifestamente ofensiva da moral e dos bons costumes

O Código Penal de 1890 previa ainda, como punição para o delito de vadiagem, a prisão por até quinze dias, a assinatura de um termo de compromisso de "tomar ocupação" no prazo de quinze dias após o cumprimento da pena de prisão, e o recolhimento dos maiores de 14 anos aos chamados "estabelecimentos industriais disciplinares". Enquanto eram bastante severos na disciplina para o trabalho, o mesmo não acontecia, no tocante à limitação de jornada. 
No início da Primeira República somente a jornada de trabalho dos menores de idade estavam sujeitas à limitação legal, prevista no Decreto 1313/1891. A idade mínima para o trabalho era de doze anos de idade e, para "aprendizagem", oito anos.

A limitação de jornada estava dividida em faixas etárias e por gênero. Meninas, dos doze aos quinze anos, não poderiam trabalhar por mais de sete horas diárias; meninos, dos doze aos catorze anos, tinham a jornada limitada em sete horas diárias e, dos catorze aos quinze, esse limite era elastecido para nove horas diárias. Os menores aprendizes, que tinham de oito a dez anos de idade, só poderiam trabalhar três horas por dia, enquanto que os aprendizes de dez a doze anos tinham jornada legal de quatro horas diárias. Ambos, com intervalos intrajornada, de meia hora e uma hora, respectivamente.

No tocante aos demais trabalhadores, vigorava o regulamento de cada fábrica quanto à limitação de jornada, até o ano de 1932. Com a edição do Decreto no 21.364/32, ficou estabelecida a jornada de oito horas diárias, ou quarenta e oito horas semanais para os empregados de estabelecimentos industriais, excluídos de sua abrangência os trabalhadores das indústrias agrícolas, de transportes em geral, marítimo ou de minas, nem os serviços de utilidade pública, federal, estadual ou municipal, a cargo de empresas particulares. Havia, no mesmo decreto, a previsão de um descanso semanal a cada seis dias trabalhados. Quanto à prorrogação de jornada, o referido dispositivo legal previa as seguintes hipóteses:

Art. 3ำ duração normal do trabalho poderá ser elevada até dez horas diárias ou sessenta horas semanais, se assim acordarem empregadores e empregados ou as convenções coletivas de trabalho, mediante pagamento de percentagem adicional sobre os salários, salvo nas indústrias insalubres ou nos trabalhos subterrâneos, cuja duração não poderá exceder de oito horas diárias.

Art. 4ำ A duração normal do trabalho poderá ser, excepcionalmente, elevada até doze horas diárias: em determinadas secções de estabelecimentos industriais, quando o seu funcionamento for imprescindível para acabar ou completar o trabalho de outras secções; nos serviços necessários para acabamento de trabalhos começados, desde que seja para prevenir estragos nas matérias primas ou nos artigos em processo de fabricação, ou, ainda, para evitar o mau resultado técnico de serviço já iniciado. 
Pouco depois, em 1934, a Constituição Federal passou a prever a jornada de trabalho de oito horas diárias e quarenta e oito horas semanais, reduzíveis, mas só prorrogáveis nos casos previstos em lei; férias anuais remuneradas e repouso hebdomadário, preferencialmente aos domingos. A Constituição de 1934 trazia o trabalho enquanto dever social e bem que o Estado deveria proteger e a disciplina para o trabalho como política pública a ser promovida através das escolas e do trabalho nos campos e oficinas. A Constituição de 1937, no tocante à duração do trabalho, manteve o previsto por sua antecessora, acrescentando apenas o repouso nos feriados religiosos e civis.

A partir de 1943, a jornada de trabalho passou a ser regulada pela CLT, que passou a cuidar: da duração do trabalho, nos artigos 58 a 65; dos períodos de descanso, nos artigos 66 a 72; do trabalho noturno, no artigo 73, além do supracitado artigo $4^{\circ}$, que traz a definição de tempo efetivo de serviço. A jornada de trabalho foi limitada a oito horas diárias, para as atividades em geral, com intervalo para repouso e alimentação de uma a duas horas, para trabalhos com duração superior a seis horas diárias, e de quinze minutos para atividades cuja duração seja superior a quatro horas e não ultrapasse seis horas.

A CLT também trouxe a possibilidade de prestar horas suplementares, em número não excedente de duas, mediante acordo escrito entre empregador e empregado, ou mediante contrato coletivo de trabalho. Além desta hipóteses, trouxe também a possibilidade de prorrogação da jornada, para além do limite legal ou convencionado por motivo de força maior ou para realização de serviços inadiáveis ou cuja inexecução possa acarretar prejuízo manifesto (ao empregador). Previa também o pagamento de adicional de, pelo menos $20 \%$, sobre o valor da hora normal para remunerar as horas extras.

Na Constituição de 1946, a jornada continua limitada em oito horas diárias, nos moldes da CLT e o trabalho permanece como um dever social, assim como na constituição de 1967, no contexto da ditadura militar. Somente em 1988, ficou estabelecida a redução jornada de trabalho - de quarenta e oito para quarenta e quatro horas semanais.

A Constituição Federal de 1988 estabelece, no inciso XIII de seu Art. 7ํㅜ, que é direito dos trabalhadores "duração do trabalho normal não superior a oito horas diárias e quarenta e quatro semanais, facultada a compensação de horários e a redução da jornada, mediante acordo ou convenção coletiva de trabalho". Esse 
direito à jornada diária de 8h é relativizado pela autorização legal (Art. 59 da CLT) à prestação de horas extraordinárias no número máximo de duas por dia, mediante acordo escrito ou contrato coletivo de trabalho e com o pagamento de adicional correspondente a não menos que $50 \%$ do valor da hora normal.

Além da possibilidade de prolongamento de jornada descrita acima, existe também a possibilidade de compensação anual de jornada (banco de horas), pactuada por acordo ou convenção coletiva. Com isso, permite-se que o excesso de horas em um dia de trabalho seja compensado pela correspondente diminuição em outro dia, desde que não seja ultrapassado o limite máximo de 10 horas por dia nem exceda em um ano a soma das jornadas semanais previstas. Em virtude da compensação de tempo, não há pagamento de adicional em dinheiro.

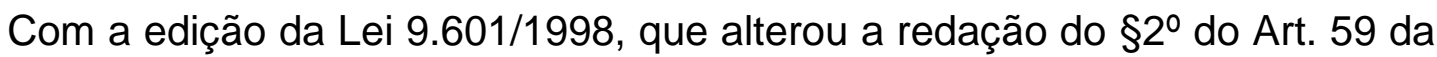
CLT, o marco temporal da compensação foi elastecido para um ano. Sendo assim, a compensação - que tinha como tempo limite o dia, a semana, o mês ou o quadrimestre de trabalho, prazo máximo antes da referida lei -, passou a ter o período de um ano para ser feita, retardando ainda mais o acesso ao tempo livre prometido ao trabalhador.

Outras formas de flexibilizar e prolongar a jornada de trabalho, diária ou semanal, do trabalhador também ganharam força nas últimas décadas - como a permissão de trabalhar aos domingos e feriados, mediante o pagamento em dobro do dia não compensado (Súmula 146 do TST) e a incorporação das "horas extras habituais" nos rendimentos do trabalhador (Súmula 291 do TST). Quanto a estas últimas, fica evidente uma contradição entre as palavras "extras" e "habituais", pois sendo extraordinária, automaticamente as horas de prolongamento de jornada não deveriam ser habituais, ainda que sejam remuneradas com o respectivo adicional. Uma coisa não pode ser e deixar de ser, ao mesmo tempo e sob os mesmos aspectos, pois vai contra a lógica maior de Aristóteles, conforme lembra, eu suas aulas e exposições, um dos autores deste texto.

Há ainda a hipótese de prorrogação de jornada por "necessidade imperiosa", caracterizada por motivos de força maior ou por serem os serviços de caráter inadiável ou cuja inexecução cause prejuízo manifesto ao empregador. Nesses casos, a jornada pode ser prolongada em até 4 horas extraordinárias, não podendo ultrapassar 10 horas de trabalho por dia, e mediante o pagamento do respectivo adicional de horas extra previsto no Art. $7^{\circ}$, XVI, da Constituição Federal. 
Cabe destacar que a maior parte dessas alterações legislativas, que permitem o prolongamento da jornada de trabalho, foram efetuadas durante 0 período que Carlos Montaño e Maria Lucia Duriguetto (2011) chamam de ofensiva contra o trabalho, após a quebra do Estado de Bem-estar. Período este em que as leis trabalhistas foram desmontadas, flexibilizadas e os trabalhadores são estimulados a autointensificar o seu trabalho. Observou-se, com isso, um fenômeno não previsto por alguns cientistas sociais, especialmente juslaboralistas: do desemprego estrutural e a nova morfologia do mundo do trabalho, na qual o trabalho subordinado deixou de abarcar a maioria da população economicamente ativa.

Para que essa ofensiva neoliberal produzisse os efeitos esperados sobre os trabalhadores, teve início um novo processo de glorificação do trabalho. Desta vez, para enfatizar a necessidade de sua intensificação, como forma de manter-se empregado. Hartmut Rosa (2014) chama este fenômeno de "Hamster Wheel Effect". Como importantes ferramentas de glorificação do prolongamento da jornada e do aumento de sua intensidade, a autora identifica a evangelização em torno das vantagens do banco de horas e da percepção de adicional por horas extras trabalhadas.

\section{A REDUÇÃO DA JORNADA DE TRABALHO NA VISÃO DA DOUTRINA JURÍDICO-TRABALHISTA TRADICIONAL.}

Maurício Godinho Delgado (2011) reconhece a necessidade de uma redução da jornada de trabalho e seus impactos sobre a vida e a saúde dos trabalhadores, assim como no mercado interno e no mundo do trabalho. $O$ autor afirma que, no âmbito da saúde no trabalho, a redução de jornada "constitui notável medida de saúde no ambiente do trabalho, por restringir o desgaste inerente à atividade laborativa".

Acredita que essa redução abriria aos trabalhadores tempo livre para ampliar os seus conhecimentos, que eles também ganhariam mais tempo para passar com suas respectivas famílias e que a redução de jornada realizaria uma redistribuição social dos ganhos de produtividade alcançados com a introdução das novas 
tecnologias, e por isso é "medida relevante de combate ao desemprego e de geração de novos postos de trabalho no sistema econômico e social do país".

Ao se posicionar em favor da redução de jornada, admite propõe que esta seja reduzida de 44 para 40 horas semanais e propõe uma modernização para estes limites. Ele também considera radicais, as reduções para 36 ou 39 horas semanais e acredita não importar a forma através da qual essa redução seja conquistada - por legislação estatal, negociação coletiva, costume ou outro mecanismo jurídico.

Amauri Mascaro Nascimento (2011) reconhece que há importantes discussões acerca da redução de jornada e sobre sua importância para a melhoria da qualidade de vida dos trabalhadores, bem como para a redução do desemprego, como forma de repartir os empregos para que o maior número de pessoas possa ter acesso a eles. O referido autor, porém, acredita ser inviável a realização da diminuição de jornada, pois, para ele, a variedade de atividades humanas e as suas diferenças são suficientes para impedir o seu sucesso.

A OIT (2009) trata da redução de jornada de trabalho a partir da ideia de work-sharing, que "consiste numa redução do tempo de trabalho destinada a distribuir um volume reduzido de trabalho entre um também reduzido (ou semelhante) número de trabalhadores, a fim de evitar demissões ou alternativamente, como adotada para criar novos empregos". Essa redução, quase sempre vem acompanhada pela redução dos salários dos trabalhadores envolvidos, proporcional ao número de horas de trabalho retiradas.

Segundo documento lançado em 2009 pela OIT, a estratégia de worksharing possui cinco elementos-chave: a) a redução de horas de trabalho dos empregados de determinada empresa, ou unidade dentro da empresa, para evitar demissões; b) redução de salário proporcional ao número de horas reduzidas da jornada; c) suplementos salariais subsidiados pelo poder público do local em que se situa a empresa ou unidade objeto de work-sharing; d) o estabelecimento de um tempo limite para a vigência das medidas de redução de jornada, que necessariamente devem ser temporárias e, e) a conexão entre as medidas de worksharing e a participação dos trabalhadores em atividades que melhores suas habilidades e qualificações.

Nesse quadro, cumpre destacar que somente as empresas que estejam comprovadamente passando por dificuldades financeiras decorrentes de crise econômica e não desencadeadas pelo empregador podem participar dos programas 
de work-sharing a serem implementados nos locais em que estejam situados. Essas medidas de proteção ao emprego, como reflexo da opção da doutrina clássica pelo trabalho subordinado, só atendem aos empregados formais, cobertos pelo sistema de seguridade social. A OIT recomenda que esses programas sejam instituídos pelos governos federais dos países que recepcionem a ideia de work-sharing.

Em 06 de julho de 2015 a Presidenta da República editou a Medida Provisória no 680, que instituiu o PPE- Plano de Proteção ao Emprego, claramente alinhada à versão da OIT sobre a já referenciada redução de jornada de trabalho. PPE tem como objetivos centrais possibilitar a preservação dos empregos em momentos de retração da atividade econômica e favorecer a recuperação econômico-financeira das empresas. Dele podem participar as empresas que estejam em dificuldades econômico-financeiras, nas condições e forma estabelecidas no Art. 6ำ do Decreto № 8.479/2015, que regulamenta o PPE.

As empresas que aderirem ao PPE poderão reduzir em até $30 \%$ a jornada de trabalho de seus empregados, com a redução proporcional do salário por até seis meses, prorrogável até o limite máximo de 12 meses. Os empregados que tiverem seu salário reduzido farão jus a uma compensação pecuniária equivalente a cinquenta por cento do valor da redução salarial e limitada a $65 \%$ do valor máximo da parcela do seguro-desemprego, durante o período de redução temporária da jornada de trabalho - procedimento a ser custeado com recursos do FAT, Fundo de Amparo ao Trabalhador. Os empregadores não podem pagar aos empregados cuja jornada for reduzida um valor inferior ao salário mínimo. Serão inclusive expulsos do programa, com ônus, caso descumpram as regras estabelecidas na MP 680 e no Decreto 8.479/2015.

A partir desta narrativa sobre as versões da doutrina jurídico-trabalhista clássica a respeito da redução de jornada, é possível perceber a timidez e insuficiência das medidas sugeridas pelos autores e atores sociais contemporâneos, no sentido de liberar o tempo dos trabalhadores. Muito longe do que previa John Maynard Keynes (1930), em sua conferência intitulada Possibilidades Econômicas para os nossos netos, quando afirmava que trabalhar "durante três horas por dia é suficiente para satisfazer o velho Adão em a maioria de nós".

Diante desse quadro, o artigo pretende apresentar uma perspectiva diferente acerca da jornada de trabalho. Mais especificamente sobre a necessidade de proibir a prestação de horas extraordinárias, como um meio fundamental para viabilizar a 
redução do tempo de trabalho, no intuito de preservar os postos de trabalho existentes e gerar novas vagas.

Os autores deste texto recorrerão às teorias jurídico-trabalhista, social e organizacional críticas, a fim de demonstrar as inconsistências das versões dominantes e discutir o tempo de trabalho a partir de ótica centrada na promoção de uma existência compatível com a dignidade humana para a classe trabalhadora.

Desejam também destacar a importância deste tema, no momento em que a classe política discute uma reforma trabalhista cujo objetivo é prolongar ainda mais o tempo de trabalho, na medida em que a proposta em discussão está centrada na prevalência do negociado sobre o legislado.

\section{NOVOS CAMINHOS PARA A JORNADA DE TRABALHO: RESTRIÇÃO E PROIBIÇÃO DAS PRORROGAÇÕES. A VISÃO DA TEORIA JURÍDICO- TRABALHISTA CRÍTICA.}

Para entender o significado do tema jornada de trabalho, Marx começa a encará-lo por meio de uma indagação:

Que é uma jornada de trabalho? Quão longo é o tempo durante o qual o capital pode consumir a força de trabalho cujo valor diário ele paga? Por quanto tempo a jornada de trabalho pode ser prolongada além do tempo de trabalho necessário à reprodução da própria força de trabalho? A essas questões, como vimos, o capital responde: a jornada de trabalho contem 24 horas inteiras, deduzidas as poucas horas de repouso sem as quais a força de trabalho ficaria absolutamente incapacitada de realizar novamente seu serviço. [...] Tempo para a formação humana, para 0 desenvolvimento intelectual, para 0 cumprimento das funções sociais, para o livre jogo das forças vitais físicas e intelectuais, mesmo o tempo livre do domingo e até mesmo no país do sabatismo - é pura futilidade! (MARX, 2013)

A luta pela diminuição da jornada de trabalho, combinada à luta por melhores salários, compõem uma pauta histórica da classe trabalhadora, desde o período da revolução industrial até o presente. Foi através da capacidade de organização e de resistência dos trabalhadores que o estado moderno estabeleceu 
as primeiras limitações à duração do trabalho, a fim de preservar da vida e a necessidade de reprodução da mão-de-obra.

Explica Arnaldo Süssekind (2010) que há algumas razões centrais que justificam a limitação da jornada de trabalho, quais sejam: a) Biológicas: pois esta limitação visa combater os problemas psicofísicos oriundos da fadiga e da excessiva racionalização do serviço; b) Social: para possibilitar o trabalhador viver, como ser humano, na coletividade a que pertence, e para gozar dos prazeres materiais e espirituais criados pela civilização, entregar-se à prática de atividades recreativas, culturais ou físicas, aprimora seus conhecimentos e conviver enfim com sua família; e c) Econômicas: para restringir o desemprego e, pelo combate a fadiga, acarretar um rendimento superior na execução do trabalho.

Além das justificativas para a limitação do tempo de trabalho acima expostas, há também os critérios que informam a maneira pela qual este tempo será limitado. De acordo com o pensamento de um dos autores deste texto (1985), são estes: a) o critério do tempo efetivamente dedicado ao trabalho, considerando como jornada apenas o tempo em que efetivamente a força de trabalho era dedicada aos serviços; b) o critério da contagem do tempo em sentido amplo, que considera como jornada de trabalho o tempo em que o empregado está aguardando ou executando ordens de seu empregador, prevalente no Brasil; c) o terceiro critério considera como jornada o tempo à disposição do empregador desde a saída do empregado de sua casa até o seu retorno.

$\mathrm{Na}$ experiência brasileira - na qual prevalece o critério da contagem de tempo no sentido amplo - a limitação de jornada foi feita tendo como centro referencial o modelo de trabalho subordinado, vendido e comprado como mercadoria, separado da vida. Isto se verifica na medida em que a limitação de jornada foi feita considerando como objeto o máximo de horas que as normas de medicina e segurança do trabalho permitem que o trabalhador esteja à disposição de seu empregador. A opção pelo número máximo de horas não considera a multiplicidade de tempos sociais existentes na vida, que permanecem inflexíveis e deixam de ser vividos pelos trabalhadores na medida em que se prolonga a jornada.

Para afastar-se das versões que gravitam em torno subordinação e do auxílio ao capital a diminuir os custos de produtividade em tempos de crise econômica, os autores deste artigo questionam a razoabilidade da permissão da prestação de horas extraordinárias, uma vez que a jornada legal de oito horas está 
pautada no modelo do máximo de horas. Questionam também não ser razoável, diante das inovações tecnológicas inseridas nos processos de trabalho - que permitem uma considerável redução do tempo social necessário para a produção e reprodução do capital - manter a jornada legal em oito horas diárias.

Criticam também os principais argumentos contrários às propostas de proibição da prestação de horas suplementares, seguida por uma redução significativa da jornada de trabalho, sem redução de salário. Não é possível acatar os seus argumentos centrados no risco de perda de competitividade internacional e no aumento do custo da força de trabalho, acompanhada pela migração dos investimentos de capital estrangeiro para áreas com menor intervenção estatal nas relações de trabalho.

Nesse sentido, resgatam as lições do jurista José Montenegro Baca (1979) em sua participação no Congresso Internacional de Direito do trabalho da UFCE, quando afirmou que

O direito do trabalho é um ordenamento que se propõe a assegurar ao homem uma existência harmônica com a dignidade da pessoa humana e por isso precisamos compreender que a dignidade humana sofre quando 0 empregado é obrigado a suportar com seu trabalho um risco da empresa. (Tradução livre dos autores)

Montenegro Baca (1979), desde o final da década de 1970, defendia a inclusão do tempo in intinere na jornada de trabalho. Para ele, desde o tempo em que sai de casa até o seu retorno para casa o empregado deve ser considerado como tempo à disposição do patrão. Se um trabalhador tem de sair de casa uma ou duas horas antes do trabalho o faz pelo dever de trabalhar, em virtude da relação de subordinação subjacente ao emprego, e não porque quer.

Ainda segundo Baca, jornada ordinária é a jornada normal de trabalho, podendo ser aquela definida em lei - oito horas no caso brasileiro - ou em convenção coletiva, respeitado o limite legal. Jornada extraordinária é a que excede - limite da jornada normal e ocorre quando o trabalhador presta serviços ao empregador nas horas do dia ou nos dias que, por direito, deveria dedicar ao seu descanso. $\mathrm{Na}$ experiência brasileira, as horas excedentes das oito diárias (regra geral), e o trabalho aos domingos e feriados, cuja flexibilização legal permite a compensação em dinheiro ou em folga correspondente em outro dia da semana.

Já na década de 1980, um dos autores deste texto (1985) afirmava que 
Se o trabalho em horário excedente é cientificamente indesejável, a jornada de trabalho não deveria ser fixada pelo número máximo de horas. A questão transcende ao aspecto jurídico, porque implica rever os dados fornecidos pela medicina do trabalho. Assim, por exemplo, se a jornada máxima fixada para uma determinada categoria profissional é de oito horas, a jornada ordinária seria de seis horas, permitindo a sua prorrogação (extraordinária, com os acréscimos salariais), por mais duas. (ANDRADE, 1985, p. 14)

As horas extras não-pagas figuram como primeiro lugar no ranking do Tribunal Superior do Trabalho, em número de ações por todo o país. Em 4ํ lugar estão as ações movidas para pleitear reflexos das horas extra nas verbas rescisórias e, em 6ำ lugar, os intervalos intrajornada não concedidos aos trabalhadores que, findo o contrato, devem ser demandados como horas extraordinárias não pagas. ${ }^{2}$ Estes dados indicam que, para os empregadores, pode ser muito vantajoso prolongar e intensificar as jornadas de seus empregados e não pagar os adicionais devidos, já que muitos não recorrem à justiça do trabalho em tempo hábil; outros, em tempo algum; os que recorrem têm sua pretensão limitada à prescrição trabalhista.

Caso seja aprovada a reforma trabalhista pretendida pelo governo Temer, ficará ainda mais difícil fiscalizar a duração do trabalho e demandar judicialmente os direitos trabalhistas. Se com uma limitação legal consolidada a aproximadamente trinta anos, sem mencionar a CLT, que data de 1943, está é a realidade expressa nos processos judiciais, é desolador imaginar o quadro das relações de trabalho, a partir da aprovação de uma reforma cujo critério central seja a prevalência do negociado sobre o legislado.

Da mesma forma que ocorria no início do período industrial, o tempo de trabalho consome grande parte do tempo de vida do trabalhador, com o objetivo não de satisfazer as necessidades individuais e sociais das pessoas, mas de gerar valor de troca, mais-valor, lucro para o capital. E de forma ainda mais sofisticada, em virtude da possibilidade de maior controle do trabalho através das novas tecnologias. Todo o tempo dedicado à produção de um valor de troca que será apropriado por outrem, que determina e dirige como este tempo deve ser gasto, é um tempo nãovivido efetivamente pelo trabalhador.

\footnotetext{
2 Dados disponibilizados pelo Tribunal Superior do trabalho no link: <http://www.tst.jus.br/documents/18640430/19001391/Ranking+de+Assunto+TRT.pdf/5ed5309c-fff9-40359896-dfd81354909a>.
} 
As horas de deslocamento do indivíduo para o seu local de trabalho, salvo nos casos em que a lei determina o seu cômputo, são completamente desconsideradas pela organização do trabalho. Nas poucas horas de descanso disponíveis, o trabalhador ainda precisa se qualificar para manter-se atrativo para o mercado, devido à instabilidade das relações de emprego atuais.

Nesse sentido os autores defendem a necessidade de combater os abusos na prestação de trabalho extraordinário, para restringir ainda mais as hipóteses em que ele poderia ocorrer. Tomando o princípio da proteção social e não a subordinação como centro referencial de suas teorizações, propõem:

a) A revisão do critério de fixação de jornada de trabalho, estruturada pelo máximo de horas, incluindo o tempo in itinere no conceito de jornada ordinária;

b) Proibição do trabalho em horário extraordinário em todas as atividades, exceto nos casos de necessidade imperiosa, nos quais o pagamento adicional não poderá ser inferior a $100 \%$ do valor da hora normal;

c) Redução da jornada ordinária para quatro horas diárias e para todas as categorias;

d) Ampliação das sanções administrativas, no sentido de fazer valer as normas proibitivas do trabalho extra, impondo pesadas multas, de forma escalonada, por cada hora extraordinária trabalhada, e até 0 fechamento de estabelecimentos.

Com a adoção dessas medidas é possível garantir a um número maior de pessoas ocupadas e manter uma razoável política de emprego, para enfrentar o desemprego estrutural, especialmente, para considerar os níveis alarmantes de desemprego no Brasil e a sua natureza estrutural. Ressalta-se, conforme afirma ANTUNES (2009), que inserir esta reivindicação no Direito ao Trabalho se torna necessária "não porque se preze e cultue o trabalho assalariado, heterodeterminado, estranhado e fetichizado, mas porque estar fora do trabalho, no universo do capitalismo vigente, significa um sofrimento ainda maior do que o daqueles que vivem do trabalho subordinado."

Os autores destacam finalmente que, durante a história do trabalho humano, as conquistas relativas à redução de jornada de trabalho não são fruto de concessão estatal ou da vontade do legislador, mas das lutas operárias. Para conseguir-se a desejada redução de jornada de trabalho para 4 horas diárias, é necessária uma 
articulação entre os antigos protagonistas das lutas sociais e os novos; mesclar as pautas de interesse laboral com as temáticas de outros grupos sociais; lutar por melhores condições de vida e de trabalho, mas sem deixar de lado a perspectiva revolucionária de ação que se dirige à modificação da ordem social vigente e do modo de produção capitalista, que espalha miséria e patologias por todo planeta.

\section{CONCLUSÃO}

Fica demonstrado que uma narrativa estruturada e sincronizada com a história da formação operária conduz ao reconhecimento segundo o qual a limitação/prorrogação da jornada de trabalho se insere no contexto da Divisão Social do Trabalho introduzida pelo Modo de Produção Capitalista, que passou a subordinar a força de trabalho ao capital.

Do ponto de vista jurídico, foi o Direito Dogmaticamente Organizado, fruto da Modernidade, quem universalizou e legitimou o trabalho contraditoriamente livre/subordinado como lócus privilegiado da sociabilidade e objeto do Direito do Trabalho.

Dentro desta visão estruturante é possível extrair os dilemas e as contradições advindas da limitação/prorrogação da jornada de trabalho $e$, particularmente, a maneira como este tema vem sendo tratado ao mesmo tempo pela teoria tradicional e pela teoria jurídico-trabalhista crítica.

Por fim, deixam os autores transparecer a visão catastrófica da reforma trabalhista que vem sendo forjada no parlamento brasileiro. A ampliação das propostas terceirizantes, num cenário de desproletarização/marginalização da força de trabalho, que convive com o desemprego estrutural, o espaço aberto é para ampliar ainda mais a exploração da mão de obra e liberar, sem freios ou limites, a prorrogação da jornada de trabalho.

\section{REFERÊNCIAS}


ANTUNES, R. C. L. Adeus ao Trabalho? Ensaios Sobre a afirmação e a negação do Trabalho. $2^{\text {a }}$ ed. São Paulo: Boitempo, 2009.

ANDRADE, Everaldo Gaspar Lopes de. Estudos de Direito do Trabalho. Recife: FASA, 1985

BACA, Jose Montenegro. Anais do Congresso Internacional de Direito do Trabalho. Fortaleza, 1979.

BRASIL. Constituição (1891) Constituição da República dos Estados Unidos do Brasil. Rio de Janeiro, 1891. Disponível em < http://www.planalto.gov.br/ccivil 03/Constituicao/Constitui\%C3\%A7ao91.htm>.

Acesso em 20 dez. 2016.

BRASIL. Decreto no 847, de 11 de outubro de 1890. Rio de Janeiro, 1890. Disponível em < http://www.planalto.gov.br/ccivil_03/decreto/1851-1899/d847.htm> Acesso em 20 dez. 2016.

BRASIL. Decreto no 1.313, de 17 de janeiro de 1891. Rio de Janeiro, 1891. Disponível em < http://www2.camara.leg.br/legin/fed/decret/1824-1899/decreto-131317-janeiro-1891-498588-publicacaooriginal-1-pe.html> Acesso em 20 dez. 2016.

BRASIL. Decreto no 21.364, de 4 de Maio de 1932. Rio de Janeiro, 1891. Disponível em < http://www2.camara.leg.br/legin/fed/decret/1930-1939/decreto21364-4-maio-1932-526751-publicacaooriginal-1-pe.html> Acesso em 20 dez. 2016.

BRASIL. Constituição (1934) Constituição da República dos Estados Unidos do Brasil. Rio de Janeiro, 1934. Disponível em < http://www.planalto.gov.br/ccivil 03/Constituicao/Constitui\%C3\%A7ao34.htm>.

Acesso em 20 dez. 2016.

BRASIL. Constituição (1946) Constituição dos Estados Unidos do Brasil. Rio de 1946.

Disponível em http://www.planalto.gov.br/ccivil 03/Constituicao/Constitui\%C3\%A7ao46.htm>.

Acesso em 20 dez. 2016.

BRASIL. Constituição (1967) Constituição da República Federativa do Brasil. Brasília, $1967 . \quad$ Disponível em http://www.planalto.gov.br/ccivil 03/Constituicao/Constitui\%C3\%A7ao67.htm>. Acesso em 20 dez. 2016.

BRASIL. Constituição Federal de 1988. Promulgada em 5 de outubro de 1988. Disponível em <http://www.planalto.gov.br/ccivil_03/constituicao/constituição.htm>. Acesso em 20 dez. 2016.

BRASIL. Decreto-lei no 5.452, de 1 de maio de 1943. Aprova a consolidação das leis do trabalho. Disponível em: <http://www.planalto.gov.br/ccivil_03/decretolei/Del5452compilado.htm> Acesso em 20 dez. 2016. 
BRASIL. Lei no 9.601, de 21 de janeiro de 1998. Disponível em: http://www.planalto.gov.br/ccivil 03/LEIS/L9601.htm Acesso em 20 dez. 2016.

BRASIL. Tribunal Superior do Trabalho. Súmula no 291. In: Súmulas, Orientações Jurisprudenciais, Precedentes Normativos. Brasília: $\overline{\text { Coordenadoria de }}$ Serviços Gráficos de Administração do Conselho da Justiça Federal, 2015.

BRASIL. Tribunal Superior do Trabalho. Súmula no 146. In: Súmulas, Orientações Jurisprudenciais, Precedentes Normativos. Brasília: Coordenadoria de Serviços Gráficos de Administração do Conselho da Justiça Federal, 2015.

BRASIL. Medida provisória no 680, de 06 de julho de 2015. Disponível em: < http://www.planalto.gov.br/ccivil 03/ Ato2015-2018/2015/Mpv/mpv680.htm> Acesso em 20 dez. 2016.

BRASIL. Decreto no 8.479, de 6 de julho de 2015. Regulamenta o disposto na Medida Provisória $\mathrm{n}^{\circ}$ 680, de 6 de julho de 2015, que institui o Programa de Proteção ao Emprego.. Disponível em: http://www.planalto.gov.br/ccivil 03/ Ato2015-2018/2015/Decreto/D8479.htm> Acesso em 20 dez. 2016.

BRASIL. Tribunal Superior do Trabalho. Ranking de ações trabalhistas por assunto. Disponível em http://www.tst.jus.br/documents/18640430/19001391/Ranking+de+Assunto+TRT.pdf/ 5ed5309c-fff9-4035-9896-dfd81354909a>. Acesso em 10/01/2017.

CALVETE, Cássio da Silva. Redução da jornada de trabalho: Uma análise econômica para o Brasil. Tese (Doutorado em Economia) - Faculdade de Economia, Universidade Estadual de Campinas, São Paulo, 2006

CARDOSO, Ana Claudia Moreira. Tempos de trabalho, tempos de não trabalho: vivências cotidianas de trabalhadores. 2007. Tese (Doutorado em Sociologia) Faculdade de Filosofia, Letras e Ciências Humanas, Universidade de São Paulo, São Paulo, 2007. doi:10.11606/T.8.2007.tde-20032008-101721. Acesso em: 201612-20.

DELGADO, M. G. Curso de Direito de Trabalho. 4 ed. São Paulo: LTr, 2011.

ANDRADE, Everaldo Gaspar Lopes de. Estudos de Direito do Trabalho. Recife: Fundação Antônio dos Santos Abranches - FASA, 1985.

KEYNES, John Maynard. Economic Possibilities for our Grandchildren. In: Essays in Persuasion, New York: W.W.Norton \& Co., 1963, pp. 358-373.

MESSENGER, Jon C. Work sharing: A strategy to preserve jobs during the global jobs crisis. Genebra: OIT, 2009 
MONTAÑO, Carlos; DURIGUETTO, Maria Lúcia. Estado, classe e movimento social. São Paulo: Cortez, 2011,p.186.

NASCIMENTO, Amauri Mascaro. Curso de direito do trabalho: história e teoria geral do direito do trabalho: relações individuais e coletivas do trabalho. 26. Ed. São Paulo: Saraiva, 2011.

ROSA, Hartmut. From Work-Life to Work-Age Balance? Acceleration, Alienation, and Appropriation at the Workplace. In: The Impact of ICT on Quality of Working Life. Viena: Springer, 2014.

SÜSSEKIND, Arnaldo. Curso de Direito do Trabalho. 3. ed. atual. e rev. São Paulo: Renovar, 2010. E-Book. ISBN-13: 978-8571477766.

THOMPSON, E.P. Costumes em comum - Estudos sobre cultura popular tradicional. São Paulo: Companhia das letras, 1998. 